\title{
Admission Procedures in Nursing Education and Training
}

\author{
Johann Steinberger \\ Department of Psychotherapy Science, Sigmund Freud University, Vienna, Austria
}

Email address:

johann.steinberger@drei.at

\section{To cite this article:}

Johann Steinberger. Admission Procedures in Nursing Education and Training. American Journal of Psychiatry and Neuroscience. Vol. 8, No. 4, 2020, pp. 65-69. doi: 10.11648/j.ajpn.20200804.11

Received: October 14, 2020; Accepted: November 2, 2020; Published: November 9, 2020

\begin{abstract}
This article discusses the difficulties encountered by nursing institutes in developing admission criteria. Eligibility requirements for training are currently based on cognitive abilities. Criteria such as empathy which is much needed for any social profession is hardly taken into consideration. The aim of this article is therefore to underscore the significance of students' psychological and mental development potential. Narcissistic and dissociative difficulties in the social professions are discussed in connection with the importance of admission criteria. The risks involved in developing criteria and the dangers of sadistic relationships of dependency are also discussed. Moreover, there is a focus on both students' functional levels of personality organization and mentalization abilities as they are used as qualification criteria within the social professions. Kernberg's Structural Interview is used to determine the functional level of an individual. The Reflective Functioning Scale by Fonagy et al. is used to assess mentalization abilities in both individual and group settings. The capacity to form relationships with others, to reflect on these and the development for psychological growth qualify students for the social professions. If training institutes focus on these capacities rather than on cognitive abilities when accepting students for training, they will be more likely to assess whether students are eligible for training.
\end{abstract}

Keywords: Nursing, Education, Personality Structures, Mentalization

\section{Introduction}

An increased demand for nursing staff in the upcoming years will most likely create a challenge for western societies [1]. As training institutes will become increasingly essential to societies, they will have to be able to guarantee that the training they offer is of the highest quality possible.

Can we assume that students are under pressure when confronted with the discrepancy between the number of nursing school applicants and the number of rejections? Or is it the other way around? Are training institutes the ones under pressure to find enough students for the training they offer?

Teachers at nursing schools are not only responsible for their students' training but must also accept responsibility towards society. Society should be able to rely on trained professionals. The less training institutes accept the responsibility for the expertise of their students, the more workplaces are likely to closely select who they choose to hire. Moreover, institutes offering further training or continuing education will most probably also be careful when it comes to accepting students for further training.
The admission criteria such as those at the Medical Faculty of the University of Vienna are focused primarily on cognitive skills. These can be measured "objectively" within a cost-effective and manageable framework. Adherence to such admission criteria, however, tend to create a homogenous student body. The medical faculty's strong preference for male medical students has furthermore given rise to the issue of gender. Future professionals' lives are closely tied with exclusion and inclusion from university faculties and training institutes. Those who are excluded experience faculties and institutes as "forbidden places" [2]. The ones who enjoy the privilege of being "inside" such "forbidden places" are in turn easily seduced into narcissistically experiencing themselves as "chosen," i.e. as intellectually superior to others. The student body may correspondingly also experience itself as superior to others.

This kind of admissions procedure promotes experiences of exclusion which make it difficult for students to learn to deal with heterogenous groups. However, many professionals such as nurses are constantly in the position of having to deal with heterogenous groups. When exclusion becomes part of the admissions procedure, group phenomena and resources 
which groups can offer are learned in homogenous groups and students are therefore not prepared to deal with their professional routine. Heterogeneity begins with the gender issue. Issues pertaining to age, cultural background, family constellations including sibling relations and education of family members are also relevant [3]. These factors contribute to cultural differences.

Experience in dealing with heterogenous groups should be a training requirement in nursing schools. Admissions criteria at schools and universities inevitably determine social phenomena. Among these are the processes of exclusion and inclusion of members of society.

When general rules which provide, assistance recede into the background, individual assessors of institutions become increasingly important. This in turn places a high demand on staff who are prone to having regressive relationships of interdependence at the workplace. The more time-consuming admission procedures become, the greater the uncertainty and the more likely that relationships of interdependence between trainers and students will develop [4]. The fact that a breeding ground for "sadistic" relationships thus develops makes it all the more important for trainers to handle relationships with students responsibly. A continuous process of thinking and reflection should help to consider the possibly "seductive" aspects of "sadistic" relationships. It is of extreme importance that both trainers and students engage in this form of reflection. Because of constantly shifting roles at training institutes and universities, both teaching staff and students must be willing to reflect on these matters.

Cognitive skills and abilities are part of a personality continuum that is reflected in the expression of a person. In other words, most people are capable of mentalization and emotional introspection and are therefore able to assess situations socially appropriate. Not only should students be able to understand and interpret such situations, but they must also be willing to engage in cognitive learning processes. The interaction between students and trainers/coaches is only possible when both are engaged in such learning processes.

\section{Structure of Personality and Mentalization}

The ability to mentalize, i.e. the willingness and ability to recognize this form of reflective thinking as essential, can be considered the basis for personality development.

As early as 1975, Kernberg pointed out that many of the problems occurring within the medical profession can be linked to an increase of students with narcissistic personality traits. Prestigious professions are especially attractive to people with narcissistic personalities who look forward to the prospect of social recognition. When, moreover, entry into professional careers is made to look overly dramatic, many will not be chosen. One of the most important advertising factors is exclusion. "What you don't easily get, inevitably increases in value" [1]. When a prestige is difficult to attain, students must be able to prove their worth. People with narcissistic character traits are naturally drawn to professions of the upper strata of society. Many highly intelligent people with narcissistic traits find themselves in leading positions within their professions. They are for some time able to perform quite well and are even creative, but in the long run their achievements tend to lack depth and substance [4]. Many training institutes, especially those of the social sectors, either reject students with narcissistic traits or persuade them to undergo psychotherapeutic treatment [5].

Two structural models with similar foundations may be used for a better understanding of human existence. Both are based on the psychoanalytic and dynamic understanding from personality.

To understand human existence, two structural models with a similar basis, founded on psychoanalysis and dynamic understanding, are used here.

The structural model according to Kernberg

The structural model according to Fonagy et al.

Ad. 1

During the late 1970s Kernberg developed a structured interview which takes into consideration intrapsychic structural characteristics and thus establishes a relationship between personality and functional level [5-7]. This kind of interview uses a psychodynamic technique based on the interviewer's ability to switch back and forth between the role of observer and participant. The interviewer is thus able to experience the interview as an intrapsychic-interpersonal dynamic event.]

Kernberg bases the interview on three structural characteristics for differentiating personality organization:

Identity integration versus identity diffusion (and the quality of relationships)

Mature or immature defense (American spelling) mechanisms

Abilities or their lack to test the reality [Ability or the lack of ability to test reality]

Structural interview:

The structural interview is representative of a balanced interplay of descriptive phenomenology, psychodynamic relationship analysis and structural diagnostics [7].

The questioning technique makes an operationalized structural diagnosis possible which may take the following forms:

The survey technique made it possible to produce an operationalized structural diagnosis. The structure was divided into:

Neurotic personality organization

Higher structured personality organization

Low personality organization

Seven aspects were taken into consideration when concluding that a certain structure was dominant:

The conclusion on this structure was made by estimating seven dimensions:

1. identity, 2. coping/rigidity, 3. primitive defense, 4. reality check, 5. quality of object relations, 6. aggression, 7. moral values 
Questions based on these dimensions make it possible for the interviewer to understand the personality organization of the interviewee.

This approach is based on the idea that certain aspects of a person's character only find expression when they are in relation with others. Internalized relationship experiences and associated changes in a person's character are made manifest in encounters with other people. Such a manifestation includes the expression of emotional reactions to others. The more emotional past experiences were, the stronger the memory of them in the present. Because of the importance of such memories for the individual, certain aspects of them are repeated in the here and now. The seven dimensions explained above represent these phenomena. They attempt to facilitate an understanding of interviewees' personality structures.

The interview is not conducted according to a predetermined structure but rather according to emerging patterns of interactions. The interviewer is therefore in a position of having to oscillate between the interviewee's emotional reactions and the rationalization of these reactions. The interview is best described as a pendular movement between spontaneous utterances and attempts to explain these by the interviewee.

Structure:

The admissions interview is divided into three parts (beginning, middle and end). Its aim is to draw conclusions about the interviewees' personality organization and to be able to assess their associated development potentials and social behavior. An example may be psychotherapists in training whose ability to understand and empathize with human suffering and possible symptoms will make them capable of practicing their profession.

Similarly, nurses in training should be able to receive the guidance they need to develop the empathy necessary to their profession. The ability to reflect on this development and to thereby become competent in initiating a similar development in others is of great importance. They should furthermore be able to describe and reflect on such development on a professional level.

At the beginning of the interview candidates are questioned about their motives for pursuing training and are asked to assess whether they consider themselves qualified for the profession.

At this stage, the interviewer's aim is to gain closer understanding of the candidates' personality and functional level. The candidates' life situation, commitments in their previous training, their potential for creativity as well as future perspectives are discussed.

In this section of the interviews, questions focus on how candidates' see themselves and other people.

Here, the interviewer may deem it necessary to address candidates' unconventional or even abnormal behavior patterns and to ask for their opinions on these.

In this section, the interviewer may want to summarize the questions and answers to be able to reflect on these with the candidates.

At the end of the interview, candidates are given the opportunity to talk about matters that they consider important or relevant to the information they have provided.

The interview usually lasts between 45 (minimum) and 90 (maximum) minutes.

Evaluation of the individual interview:

candidates' subjective experience

candidates' conduct during the interview

reflection on the interviewer's feelings to help understand the candidates' internalized relationship structures

This interview technique is based on Kernberg's theory of three different levels of personality organization and is an important tool for the assessment of personality structures. It offers an objective basis for training institutes' admissions criteria [6].

Ad. 2.

Another tool for assessing training candidates is Fonagy's reflective functioning scale and the mentalized affectivity scale by jurist, which makes a qualitative and quantitative assessment of the ability to mentalize [8,9].

Mentalization refers to the ability of a person to view himor herself and others as psychic entities with mental and emotional parts which can be reflected upon. The ability to mentalize develops through bonding with others and having relationships which may change or develop over time [10].

The ability to mentalize may give insight into the psychological development and further potential for development of the persons tested.

The reflective functioning scale (RFS) was translated and slightly modified by Elke Dauert [11]. It includes the following categories:

Special mention of mental health: The self and others are represented as thinking and feeling entities. Interpersonal knowledge is explicitly described as a process in which observations and conclusions about these is conveyed; the anticipation of others' reactions which are seen in relation to a mental state.

Empathy with the characteristics of mental state: Recognition of the fallibility of all knowledge; explicit recognition of the limited power of wishes, desires and thought in the real world; knowledge that mental conditions may be concealed while retaining the principle of the mental causation of behavior.

Empathy for the complexity, difference and diversity of mental states: Explicit recognition of the possibility of different perspectives and points of view; consideration of a complex causation principle in the social world and recognition that a physical causality principle is a poor model for the mental world; recognition that social roles may interact and that the same person may have different character traits for various others.

Special efforts to link observable behavior with mental states: Recognition that observable behavior can be influenced by mental and emotional well-being; knowledge of the possibility that feelings other than those actually felt can be expressed; knowledge of the possibility of consciously deceiving others by a self-serving self-portrayal.

Recognition of the possibility of changing mental states 
and corresponding behavior: Developmental-psychological knowledge about the possibility that the mental-emotional conditions can change; considering intergenerational aspects connections.

These categories of observation enable the interviewer to make conclusions about the psychological models available to a person wanting to describe both his (or her) as well as others' thoughts and feelings. The questions asked in the interview are a prerequisite for this survey.

A nine-part scale is used to evaluate the knowledge gained in the interviews.

A score from -1 to 3 is considered problematic for candidates who would like to work with others. Usually they are unable to regard themselves and others as intentional participants of an encounter. Candidates' analytic thinking and descriptive reflection are experienced as being incongruent and showing little if any affect or emotion.

Candidates' with a score of 4-6 are able to describe their mental worlds but these seem imprecise and permeated by projections.

Candidates with a score of 7-9 can give reflected descriptions about themselves and others and are able to have dynamic subjective experiences [12].

The duration of the interview ranges from 45 minutes (minimum) to 90 minutes (maximum).

By using parts of both interview templates (Structural Interview according to Kernberg and RFS) and adapting them to our purposes we have developed a useful tool for the assessment of candidates' developmental potential, psychological structure and mentalization ability.

\section{Conclusion}

One important conclusion about the personality structures described in this essay is that the phenomena described are not primarily linked to cognitive abilities. They can therefore not be adequately measured with intelligence tests!

We are not discussing "pathological" non-functioning of certain people but are rather attempting to identify a specific psychological structure. This structure points to difficulties such people may have in approaching others while maintaining the ability to reflect and develop an empathic understanding of these others.

Interviews or role-plays during group sessions can help ascertain candidates' mentalization abilities. Moreover, non-verbal communication may be used to ascertain whether candidates are able to mentalize without language, i.e. to express feelings and attitudes through artistic expression. Lastly, candidates may reveal their ability to empathize with others through creative role interpretations in group sessions.

The ability to create an emotional bond is essential to encounters with others $[13,14]$. During role play fundamental information about the structure, scope and variability of role patterns can be identified. The interpersonal network can also in this way be assessed. Role fixations may come to the fore or essential aspects of roles may be split off. In the case of more serious emotional problems, role perception and/or the assumption of roles may be impaired. Only when a person is fundamentally able to mentalize, i.e. to assume the perspective of another person, can roles be easily assumed. Not only narcissistic phenomena but also shame and guilt conflicts may reveal themselves in role plays. Group interactions make the manifestation of such phenomena more readily visible than individual sessions. The focus of the assessment of candidates lies in the scenic interaction of the group members [15-17].

The most important requirement for student admission to the school is the developmental potential and the basic ability to perform cognitive tasks. Candidates who can understand social interaction in a way that enables them to reflect on it adequately. If they are capable of such an abstraction, it can be assumed that they will be able to act spontaneously and to adjust to a multitude of situations. Staff members should be able to show clarity and transparency when making their admission decisions known. Responsibility not only towards students but also towards society in its entirety begins with training. Any training should reflect the philosophy and culture of an institution.

\section{References}

[1] (http://www.zeit.de/wirtschaft/2017-04/pflegekraefte-mangelzuverlaessliche-zahlen-studien 17.12.2017.

[2] Mikunda, Christian (1997): Der Verbotene Ort oder die inszenierte Verführung. Unwiederstehliches Marketing durch strategische Dramaturgie. Düsseldorf: Verlag ECON, p. $116 \mathrm{f}$.

[3] Rieken, Bernd; Sindelar, Brigitte; Stephenson, Thomas (2011): Psychoanalytische Individualpsychologie in Theorie und Praxis. Psychotherapie, Pädagogik, Gesellschaft. 1 Auflage [S1.] Wien: Springer, p. 56 f.).

[4] Kernberg, Otto F. (1998): Dreißig Methoden zur Unterdrückung der Kreativität von Kandidaten der Psychoanalyse. In: Psyche 52, 1998, S. 799-834, p. 781).

[5] Kernberg, Otto F. (1978): Borderline-Störungen und pathologischer Narzissmus. 2. Aufl. Frankfurt a.M.: Suhrkamp (Literatur der Psychoanalyse), p. 40 f; p. 264; p. 288).

[6] Buchheim, Peter; Doering, Stephan; Kernberg, Otto F. (2012): Das Strukturelle Interview. In: Susanne Hörz und Stephan Doering (Hg.): Handbuch der Strukturdiagnostik. Konzepte, Instrumente, Praxis; mit 29 Tabellen. Stuttgart: Schattauer, S. 12-51; p. 12; p. $23 \mathrm{f}$.

[7] Buchheim, Peter; Cierpka, Manfred; Kächele, Horst; Jimenez, JP. (1987): Das "Strukturelle Interview" - ein Beitrag zur Integration von Psychopathologie und Psychodynamik im psychiatrischen Erstgespräch. In: Fundamenta psychiatrica 1, S. $154-161$, p. $154 \mathrm{f}$.

[8] Fischer-Kern, Melitta; Fonagy, Peter (2012): Die Reflective Functioning Scale. In: Susanne Hörz und Stephan Doering (Hg.): Handbuch der Strukturdiagnostik. Konzepte, Instrumente, Praxis; mit 29 Tabellen. Stuttgart: Schattauer, S. $225-255$, p. $231 \mathrm{f}$. 
[9] Jurist, Elliot (2018): Minding Emotions. Cultivating Mentalization in Psychotherapy. The Gilford Press, New York, p. 171f.

[10] Steinberger, Johann; Sieberth, Wolfgang; Zeman, Ewa (2013): P2: Ein mentalisierungsgestütztes Pädagogik-Konzept in der Ausbildung für Krankenpflegepersonal. In: HBScience 4 (S2), S. 30. DOI: 10.1007/s16024-013-0189-5.

[11] Daudert, Elke (2001): Selbstreflexivität, Bindung und Psychopathologie. Zusammenhänge bei stationären Gruppenpsychotherapie-Patienten. Hamburg: Dr. Kovac, p. 58 f., p. $213 \mathrm{f}$.

[12] Daudert, Elke (2002): Die Reflective Self Functioning Scale. In: Ulla Bade, Bernhard Strauß und Strauß-Buchheim-Kächele (Hg.): Klinische Bindungsforschung. Theorien - Methoden Ergebnisse; mit 22 Tabellen. Stuttgart [u.a.]: Schattauer, S. 54-67, p. 60).

[13] Orlinsky, D. E.; Ronnestad, M. H. \& Willutzki, U. (Hg.) (2004): Fifty years of psychotherapy processoutcome research: Continuity and change. In: M. Lambert (Hg.): Handbook of
Psychotherapy Research and Behavior Change. New York. Wiley (S. 307-389), p. 307 f.

[14] Buchholz, Michael B. (2008): Wirkt der Therapeut oder die Methode? In: Psycho-News-Letter DGPT (98). Online verfügbar unter http://dgpt.de/fileadmin/download/psychonewsletters/PNL45.pdf, zuletzt geprüft am 15.01.2015, p. 1 f.

[15] Tschuschke, Volker (2001): Psychodrama. Indikationsbereich und Diagnostik im Psychodrama. In: Volker Tschuschke und Yvonne M. Agazarian (Hg.): Praxis der Gruppenpsychotherapie. Mit 49 Tabellen. Stuttgart [u.a.]: Thieme, S. 373-374, p. 373 f.

[16] Schacht, Michael (2010): Das Ziel ist im Weg. Störungsverständnis und Therapieprozess im Psychodrama. 2. durchgesehene Auflage, Wiesbaden: VS Verlag für Sozialwissenschaften / GWV Fachverlage, p. 52.

[17] Stadler, Christian; Kern, Sabine (2010): Psychodrama. Eine Einführung. 1. Auflage. Wiesbaden: VS Verlag für Sozialwissenschaften (Lehrbuch), p. 87). 